\title{
Vinyl Ruthenium Carbenes: Valuable Intermediates in Catalysis
}

\author{
Damián Padín, Jesús A. Varela and Carlos Saá
}

Centro Singular de Investigación en Química Biolóxica e Materiais Moleculares (CIQUS), e Departamento de Química Orgánica, Universidade de Santiago de Compostela, 15782

Santiago de Compostela, Spain

jesus.varela@usc.es, carlos.saa@usc.es

\begin{abstract}
Vinyl ruthenium carbenes are easily prepared from the neutral $\mathrm{Ru}(\mathrm{II})$ complex $\mathrm{Cp} * \mathrm{RuCl}(\mathrm{cod})$ in the presence of functionalized alkynes and diazoalkanes. These intermediates have been proposed for several transformations in which the nature of the products are strongly dependent of the functionality on the alkyne substituents. New modes of catalytic cyclizations due to the electrophilicity of these vinyl ruthenium carbene intermediates are presented in this chapter. Alkynyl acetals, ethers and amines gave rise to complex bicyclic structures, spiro- and fused, in an intramolecular redox, neutral process that involved [1,n]-hydrogen transfers/cyclization. New catalytic heterocyclizations have been also achieved by trapping the in situ generated vinyl ruthenium carbenes with $\mathrm{O}$ - and N-nucleophiles from alkynals/alkynones and alkynylamines.
\end{abstract}

Keywords alkynyl derivatives, benzoxazines, bicyclic compounds, carbenes, catalysis, cyclization, heterocycles, ruthenium, vinyl ruthenium carbenes.

\section{Introduction}

Metal carbene complexes have proven their value in synthetic chemistry due to the number of catalytic organometallic transformations in which they are involved.[1] For example, metal carbenes have been investigated in a wide variety of catalytic alkene metathesis transformations such as cross metathesis (CM), ring-closing metathesis (RCM), acyclic diene metathesis (ADMET), and ring-opening metathesis polymerization (ROMP),[2-9] as well as in reactions involving alkynes such as alkyne polymerization,[10-12] enyne metathesis,[13-15] cyclopropenation,[16] etc. 
Other in situ generated metal carbenes, either from diazo compounds or from activation of alkynes with electrophilic metals,[1,17,18] have been considered as key intermediates for catalytic cyclopropa(e)nation reactions, X-H insertions or intricate skeleton rearrangements.[19-26]

Conjugated vinyl ruthenium carbenes D (Scheme 1), smoothly prepared under mild conditions by treatment of neutral $\mathrm{Ru}(\mathrm{II})$ complex $\mathrm{Cp} * \mathrm{RuCl}(\mathrm{cod})$ in the presence of functionalized alkynes and diazoalkanes, have been recently proposed in catalytic transformations that involve the formation of carbon-carbon bonds.[27]

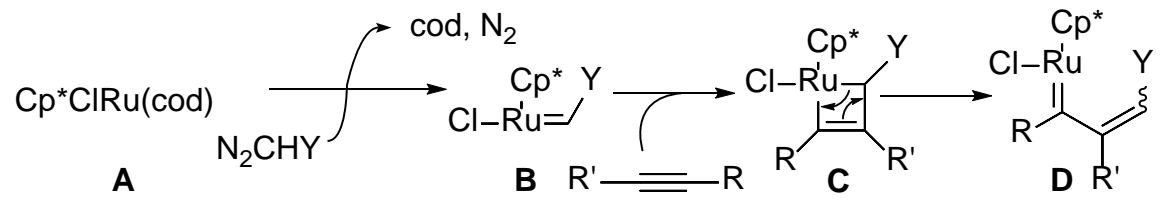

Scheme 1. Mechanistic hypothesis for the formation of vinyl ruthenium carbenes from $\mathrm{Cp} * \mathrm{ClRu}(\mathrm{cod})$ in the presence of diazo compunds and alkynes.

The type of the reaction products is strongly dependent on the nature of the alkyne functionality (Scheme 2). Functionalized 1,3-dienes could be catalytically obtained by a) trapping the initially formed vinyl ruthenium carbene with a second molecule of a diazo compound[28,29] and b) Rautenstrauch rearrangement of propargylic carboxylates followed by trapping of the transient vinyl ruthenium carbene with a diazoalkane.[30] In addition, c) enynes bearing terminal triple bonds led to alkenyl bicyclo[3.1.0] hexanes,[31,32] d) disubstituted 1,6-enynes at the propargylic positions afforded $\alpha$-alkenyl alkylidene cyclopentanes,[33] while e) 1,6-allenynes were converted to E,Z-mixtures of $\alpha$-alkenyl alkylidenes bicyclo[3.1.0]hexanes.[34]

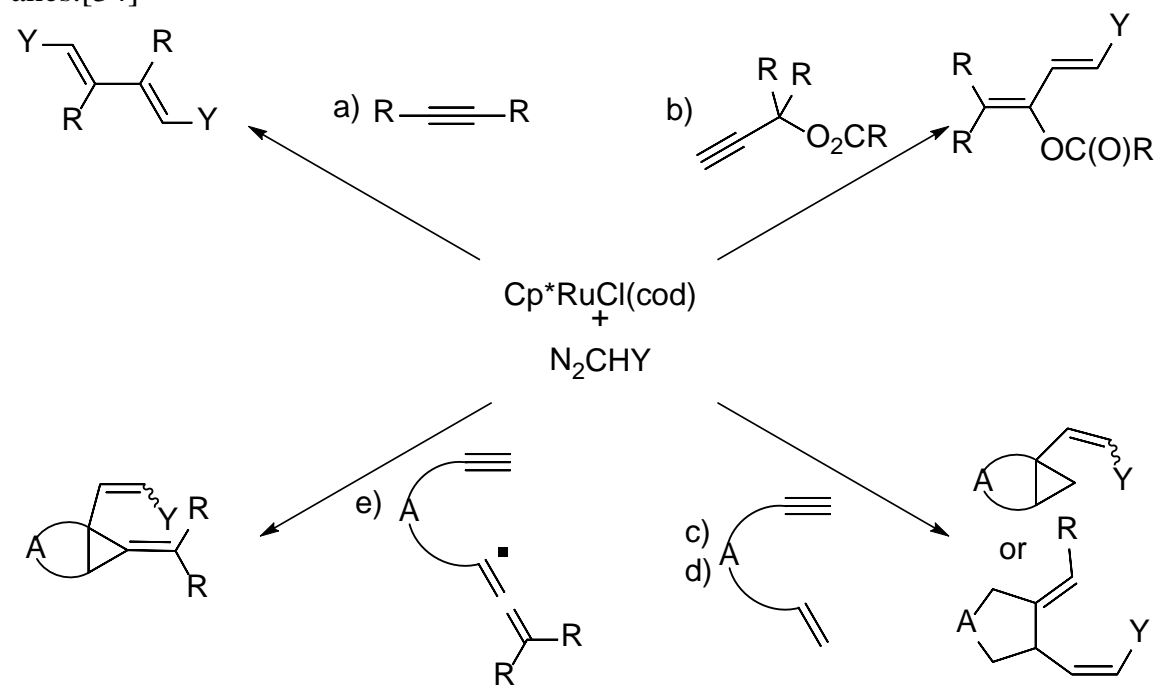


Scheme 2. Type of products obtained by reaction of catalytic amounts of $\mathrm{Cp} * \mathrm{RuCl}(\mathrm{cod})$ with diazo compounds and alkynes.

In all the previous transformations the vinyl ruthenium carbene intermediate evolves to the final products via non-polar mechanisms (reductive eliminations, [2+2] cycloadditions and 1,2-insertions). This chapter will be devoted to the synthetic opportunities (new catalytic cyclizations) derived from the polar chemistry of vinyl ruthenium carbene intermediates (electrophilic carbenes). New carbo- and heterocyclizations by intramolecular nucleophilic attack to the ruthenium carbene intermediates will be described. Specifically, the neutral redox processes in which an activated hydrogen (a "hydride") is intramolecularly transferred to the ruthenium carbene and the nucleophilic attack of oxygenated and nitrogenated nucleophiles will be presented. Finally, computational calculations would rationalize the stereoselectivity observed for such transformations.

\section{Intramolecular Ruthenium Catalyzed Redox, Neutral [1,n]-Hydride Transfer/Cyclization Processes}

The functionalization of relatively unreactive C-H bonds remains a major topic in organic synthesis, particularly from the viewpoint of sustainability and efficiency, since new C-C and C-heteroatom bonds can be directly formed without previous prefunctionalization.[35-40] For this purpose, a large number of methodologies have been developed, being most of them oriented to the transition metal-catalyzed $\mathrm{C}\left(s p^{2}\right)$-H activation, while the most difficult $\mathrm{C}\left(s p^{3}\right)$-H activation still remains a challenge owing to its high bond dissociation energy. The intramolecular redox, neutral [1,n]-hydride transfer/cyclization processes has emerged as one efficient and powerful method for selective activation and direct functionalization of inactive $\mathrm{C}\left(s p^{3}\right)$ $\mathrm{H}$ bonds towards 5-, 6- and 7-membered carbo-, hetero-, spiro-, or fused cycles.[41,42]

Vinyl ruthenium carbene intermediates, obtained by treatment of catalytic $\mathrm{Cp} * \mathrm{RuCl}(\mathrm{cod})$ with (trimethylsilyl)diazomethane and alkynylacetals, ethers or amines, can act as hydride acceptors in intramolecular [1,n]-hydride transfers to afford functionalized spiro- and fused bicycles.[43] Tertiary $\mathrm{C}\left(s p^{3}\right)-\mathrm{H}$ of cyclic and acyclic acetal derivatives of alkynals could be activated under the mild conditions to generate vinyl ruthenium carbenes to give the corresponding functionalized cyclic compounds resulting from a [1,5] and [1,6]-hydride transfer/cyclization in good yields (Scheme 3). 
<smiles>C#CCC(C)(C(=O)OC)C1OCCO1</smiles><smiles>[R]C([R])(C#C)C(C)(COC)CC(OCC)OCC</smiles>
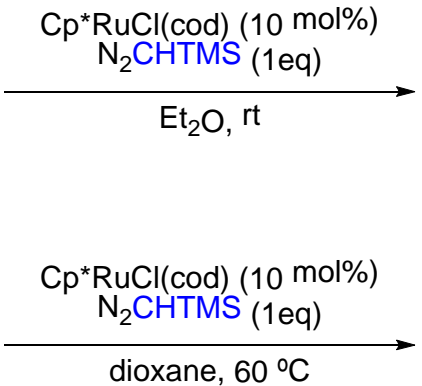
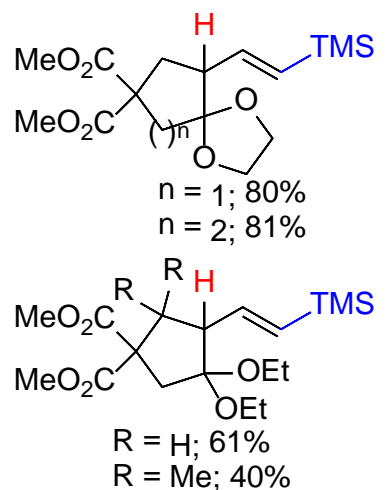

Scheme 3. Ruthenium-catalyzed tertiary [1,5]- an [1,6]-hydride transfer/cyclization in alkynyl acetals.

Gratifyingly, the less activated tertiary $\mathrm{C}\left(s p^{3}\right)-\mathrm{H}$ of alkynyl tetrahydrofurans and pyrans $(X=O, n=1,2)$ or pyrrolidines $(X=N)$ underwent the $[1,5]$ and $[1,6]$ hydride transfer/cyclization processes to afford the oxa- and azaspiranic bicycles in fairly good yields with good diastereoselectivity or as single diastereomer, respectively (Scheme 4).
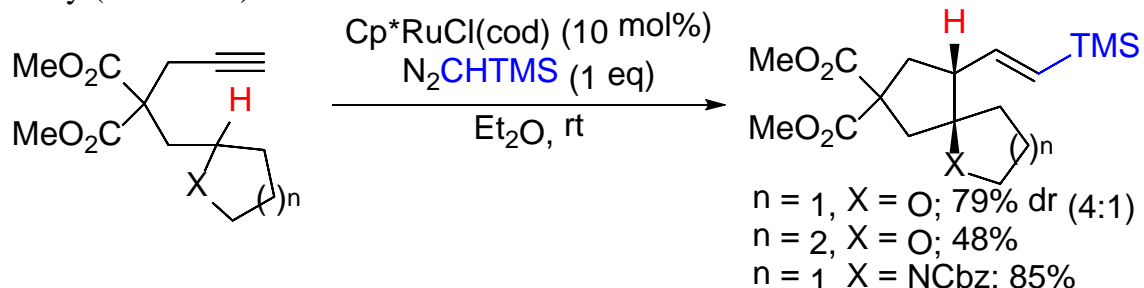

Scheme 4. Ruthenium-catalyzed tertiary [1,5]- and [1,6]-hydride transfer/cyclization in alkynyl tetrahydrofurans/pyrans and pyrrolidines.

Even the alkynyl ethers bearing secondary $\mathrm{C}\left(s p^{3}\right)$ - $\mathrm{H}$ also underwent [1,5]-hydride transfer/cyclization processes in moderate to good yields. Trans homoallylic ethers (mono- and bicyclic structures) could be obtained from acyclic ethers and tetrahydrofurans, respectively (Scheme 5). Secondary $\mathrm{C}\left(s p^{3}\right)-\mathrm{H}$ of amines could also be activated to give the corresponding bicyclic piperidine derivative as a single diastereoisomer. 


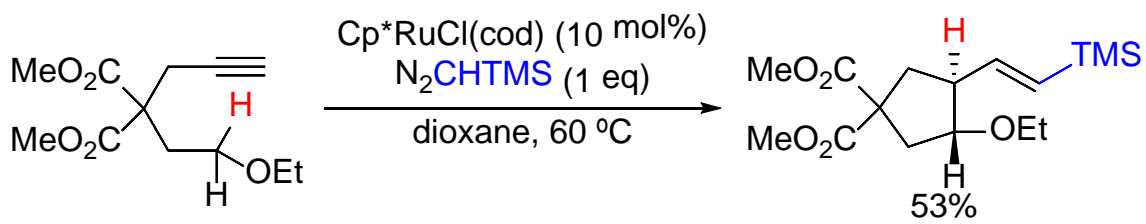<smiles>C#CCC(COC)(C(=O)OC)C1CCOC1</smiles>

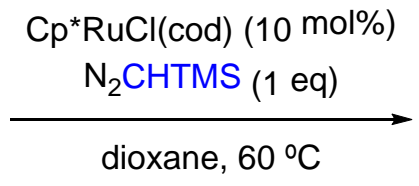<smiles>COC(=O)C1(C(=O)OC)CC(/C=C/C#N)C2OC(=O)CC21</smiles><smiles>C#CCC(COC)(COC)C1CCCN(C(=O)OC)C1</smiles>

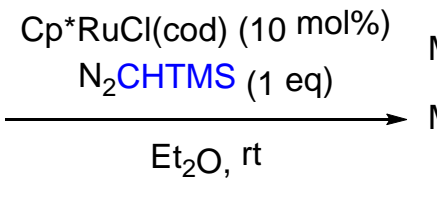

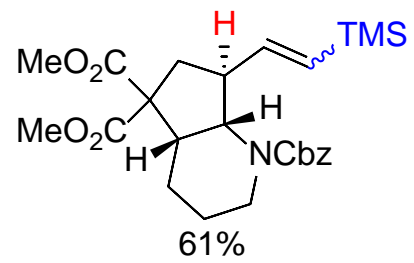

Scheme 5. Ruthenium-catalyzed secondary [1,5]-hydride transfer/cyclization in alkynyl ethers and piperidines

The proposed mechanism for the Ru-catalyzed intramolecular redox, neutral $[1, \mathrm{n}]$-hydride transfer/cyclization processes is shown in Scheme 6. The starting neutral precatalyst ruthenium(II) complex in the presence of the (trimethylsilyl)diazomethane and the alkyne would easily form the ruthenium carbene complex I, which smoothly evolves to the conjugated vinyl ruthenium carbene species II. This complex would undergo a [1,5]-hydride transfer to the electrophilic carbene assisted by the heteroatom(s) to afford a transient oxonium ion which is trapped to give the ruthenacycle III. Finally, reductive elimination would give rise to the spiro compound with recovery of the catalytic Ru(II) species. 


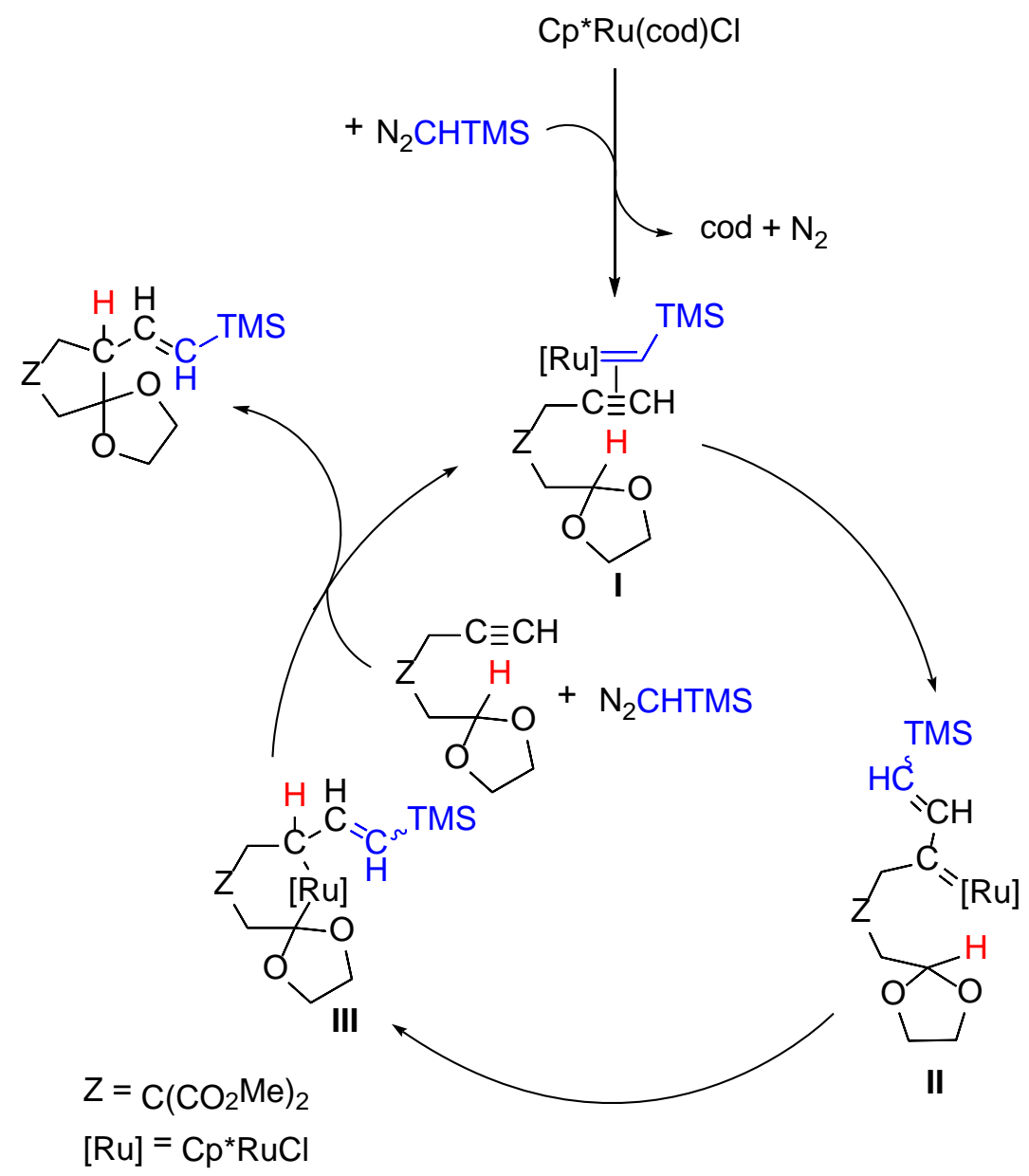

Scheme 6. Mechanistic hypothesis for the Ru-catalyzed intramolecular redox, neutral [1,n]-hydride transfer/cyclization processes.

\section{Heterocyclizations via Vinyl Ruthenium Carbene Intermediates from Alkynals and Alkynones}

New catalytic heterocyclizations have been also achieved by trapping the in situ generated electrophilic vinyl ruthenium carbenes (obtained by treatment of catalytic amounts of $\mathrm{Cp} * \mathrm{RuCl}(\mathrm{cod})$ with alkynals/alkynones and (trimethylsilyl)diazomethane) with $O$-nucleophiles from the carbonyl functionalities. Indeed, 
3,3-disubstituted and 3,3,4-trisubstituted alkynals afforded the corresponding 2-vinyl-3,4-dihydropyrans in good yields with high diastereoselectivity (Scheme 7).[44]
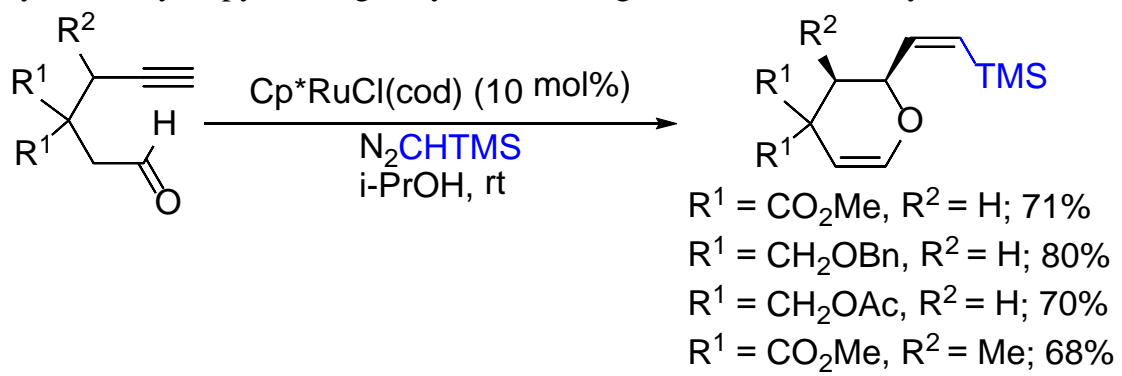

Scheme 7. Ruthenium-catalyzed heterocyclization of alkynals to 2-vinyl-3,4-dihydropyrans.

The diastereoselectivity of the reaction was further evaluated by using 3-monosubstituted alkynals as starting materials. Alkynals bearing methoxycarbonyl, benzyloxymethyl and acetoxymethyl substituents gave rise to the corresponding 2-vinyl-3,4-dihydropyrans as single cis diastereomers (Scheme 8). However, alkynals bearing bulkier 3-silyloxy substituents showed lower diastereoselectivity for the heterocyclization process.

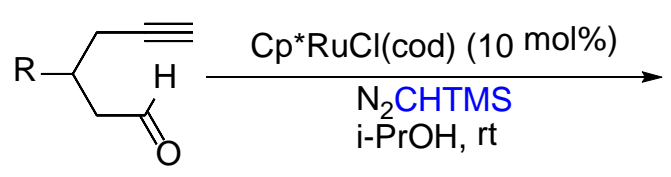<smiles>[R]C1C=CO[C@@H](/C=C\C(C)(C)C)C1</smiles>

$\mathrm{R}=\mathrm{CO}_{2} \mathrm{Me} ; 25 \%$, cis isomer

$\mathrm{R}=\mathrm{CH}_{2} \mathrm{OBn} ; 72 \%$, cis isomer

$\mathrm{R}=\mathrm{CH}_{2} \mathrm{OAc} ; 68 \%$, cis isomer

$\mathrm{R}=$ OTBS; $72 \%$, cis:trans 3.3:1

R = OTIPS: $82 \%$, cis:trans 4:1

Scheme 8. Diastereoselectivity of the ruthenium-catalyzed heterocyclization of 3-alkynals to 2vinyl-3,4-dihydropyrans.

6-Substituted 2-vinyl-3,4-dihydropyrans could also be achieved by ruthenium catalyzed heterocyclization of alkynones instead of alkynals (Scheme 9). The heterocyclization of 3-monosubstituted alkynones showed complete diastereoselectivity to give the cis 2,4,6-trisubstituted dihydropyrans, which could be applied to the obtention of enantiomerically pure dihydropyrans by just starting from $(R)$ 3-(tertbutylsilyloxy)alkynones (Scheme 9). 


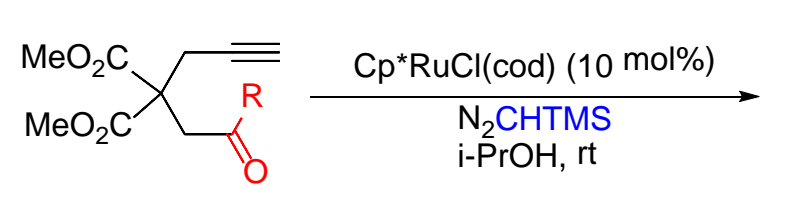

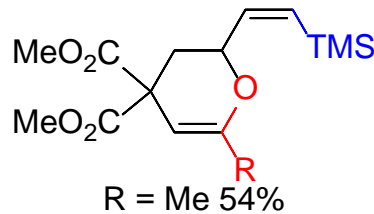

$\mathrm{R}=\mathrm{Me} 54 \%$

$\mathrm{R}=\mathrm{Ph} 70 \%$

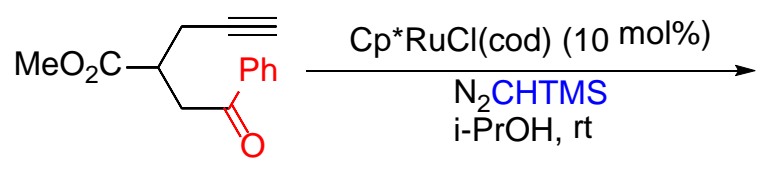<smiles>COC(=O)[C@H]1C=C(c2ccccc2)O[C@@H](/C=C\C(=O)OC(C)(C)C)C1</smiles><smiles>[R]C(=O)CC([R])CC#C</smiles>

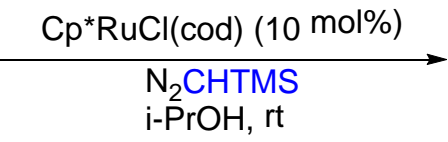<smiles>[Y15]C(=[R])C=[R]1C=C([R])C=C([R])O1</smiles>

$\mathrm{R}=\mathrm{Me} 68 \%$

$\mathrm{R}=\mathrm{Ph} 70 \%$

Scheme 9. Ruthenium-catalyzed heterocyclization of alkynones to 6-substituted 2-vinyl-3,4-dihydropyrans and studies of diastereoselectivity.

$N$-Tethered alkynals and alkynones also cyclized under the typical catalytic reaction conditions (diethyl ether as solvent) to give the corresponding 2-vinyl-3,4dihydro-2H-1,4-oxazines in moderate to good yields (Scheme10).

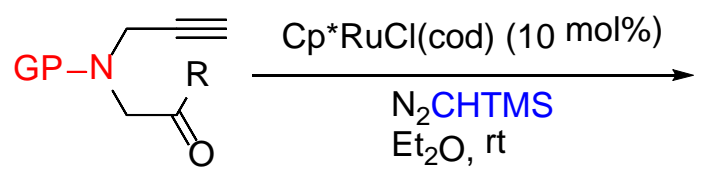<smiles>[R]C1=CN([PH-])CC(/C=C\C(C)=S)O1</smiles>

$$
\begin{aligned}
& \mathrm{GP}=\mathrm{TolO}_{2} \mathrm{~S}, \mathrm{R}=\mathrm{H} ; 58 \% \\
& \mathrm{GP}=\mathrm{TisSO}_{2}, \mathrm{R}=\mathrm{H} ; 57 \% \\
& \mathrm{GP}={ }^{t} \mathrm{BuOCO}, \mathrm{R}=\mathrm{H} ; 58 \% \\
& \mathrm{GP}=\mathrm{BnOCO}, \mathrm{R}=\mathrm{H} ; 55 \% \\
& \mathrm{GP}=\mathrm{Ts}, \mathrm{R}=\mathrm{Ph} ; 87 \%
\end{aligned}
$$

Scheme 10. Ruthenium-catalyzed heterocyclization of $N$-tethered alkynals and alkynones to 2vinyl-3,4-dihydro-2H-1,4-dihydrooxazines.

The proposed mechanism for the Ru-catalyzed heterocyclization of alkynals and alkynones to give 2-vinyl-3,4-dihydropyrans (and 2-vinyl-3,4-dihydrooxazines, not shown) is depicted in Scheme 11. It would start with the initial formation of the electrophilic vinyl ruthenium carbene intermediate II that undergoes a nucleophilic attack of the carbonyl to afford the zwitterionic intermediate III. The diastereoselectivity of the process could be rationalized if the nucleophilic attack of the 
carbonyl takes place through the more stable chair-like conformer of the ruthenium carbene IIa with all the substituents in equatorial position. Final deprotonation and reprotonation of the C-Ru bond would afford the observed dihydropyran with recovery of the catalytic species.

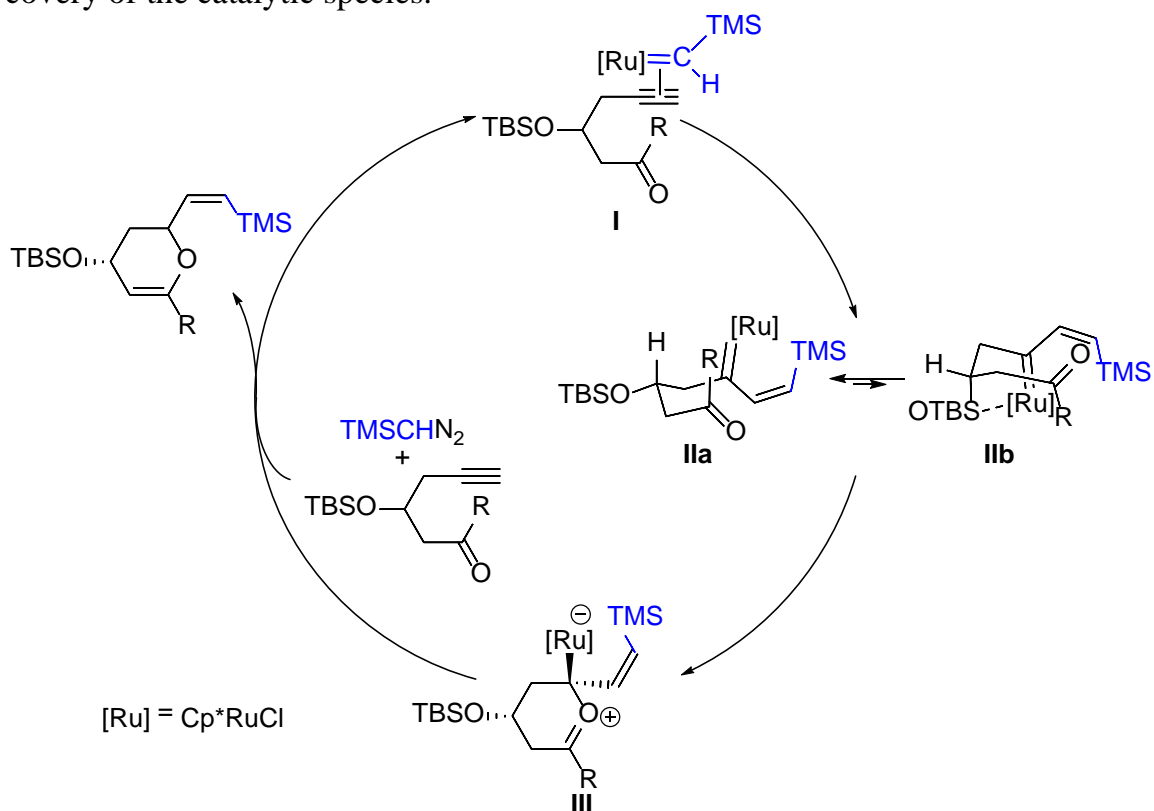

Scheme 11. Proposed mechanism for the ruthenium-catalyzed heterocyclization of alkynals and alkynones

\section{Heterocyclizations via Vinyl Ruthenium Carbene Intermediates from otho-(Alkynyloxy)benzylamines}

Other catalytic heterocyclizations have been achieved by trapping the in situ generated electrophilic vinyl ruthenium carbenes (obtained by treatment of catalytic amounts of $\mathrm{Cp} * \mathrm{RuCl}(\mathrm{cod})$ with $\omega$-alkynyl benzylamines and (trimethylsilyl)diazomethane) with $N$-nucleophiles from benzylamine derivatives. Indeed, rutheniumcatalyzed intramolecular heterocyclization of ortho-(alkynyloxy)benzylamines gave rise to 2,2-disubstituted dihydro-1,3-benzoxazines, which would involve a nucleophilic attack of the amine to the in situ generated vinyl ruthenium carbene intermediate followed by a skeletal rearrangement (Scheme 12).[45] The presence of the oxygenated tether was crucial for the rearrangement since the corresponding alkynyl benzylamine afforded the linear conjugated diene instead the cyclized 
product (probably by $\beta$-hydrogen elimination from the vinyl ruthenium carbene intermediate).

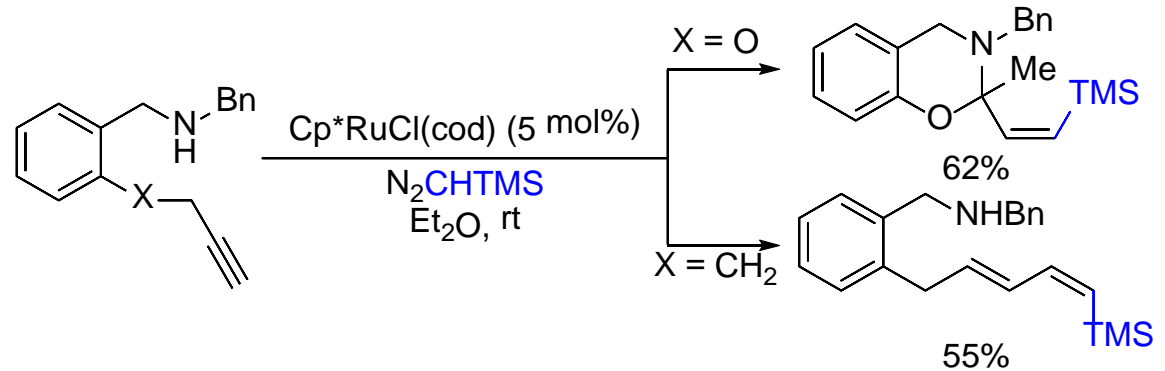

Scheme 12. Ruthenium-catalyzed reactions of C- and O-tethered ortho-alkynylbenzylamines

Substitution on the aromatic ring of benzylamines is well tolerated for this transformation (Table 1). Both electron-donating and electron-withdrawing substituents are well accepted since the corresponding 1,3-benzoxazines were obtained in reasonably good yields being slightly better for electron-poor aromatic rings. On the other hand, functionalized halo-1,3-benzoxazines could be easily prepared using this methodology, which facilitates other functionalizations by further manipulations, with the exception of the ortho bromo substituted 1,3-benzoxazines due, most probably, to steric reasons.<smiles>[R]CCC#CCOc1ccccc1CNCc1ccccc1</smiles>

$55 \%$<smiles>CC1(/C=C\C(=S)S(C)(=O)=O)Oc2cc(Cl)ccc2CN1Cc1ccccc1</smiles>

$52 \%$<smiles>CC1(/C=C\C(N)=S)Oc2ccc(C(F)(F)F)cc2CN1Cc1ccccc1</smiles>

$58 \%$<smiles>CC(C)(C)/C=C\C1(C)Oc2cccc(Br)c2CN1Cc1ccccc1</smiles>

$70 \%$<smiles>[R][R]1ccc2c(c1)CN(Cc1ccccc1)C(C)(/C=C\[Y5](C)(C)C)O2</smiles><smiles>[Y15]CC1(/C=C\CS(C)(=O)=O)Oc2ccc([X])cc2CN1Cc1ccccc1</smiles>

$\mathrm{X}=\mathrm{Br} 81 \%$ $\mathrm{X}=\mathrm{Cl} 73 \%$<smiles></smiles>

$0 \%$

Table 1. Ruthenium-catalyzed heterocyclization of aryl substituted ortho-(alkynyloxy)-benzylamines to 1,3-benzoxazines.

ortho-(Alkynyloxy)benzylamines bearing alkynyl substituents also cyclized to give the corresponding 1,3-benzoxazines in fairly good yields, although longer 
reaction times, high catalyst loadings and/or heating to $65^{\circ} \mathrm{C}$ was necessary to proceed (Scheme 13).

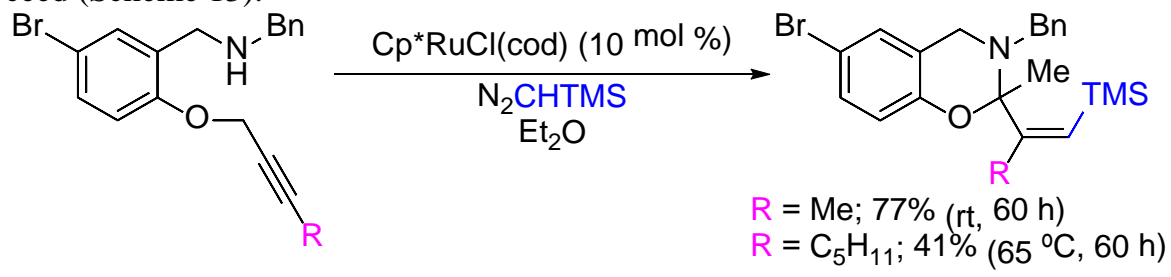

Scheme 13. Ruthenium-catalyzed heterocyclization of alkynyl substituted ortho-(alkynyloxy)benzylamines to 1,3-benzoxazines.

Primary and secondary alkyl substituted benzylamines such as propyl and cyclohexyl are well tolerated and gave rise to the corresponding 1,3-benzoxazines in good yields. In the case of the $N$-allyl substituted benzylamine, the recovery of the allyl group intact seems to indicate that polar nucleophile/electrophile interactions dominate the reactivity of the putative carbene intermediate (Scheme 14).

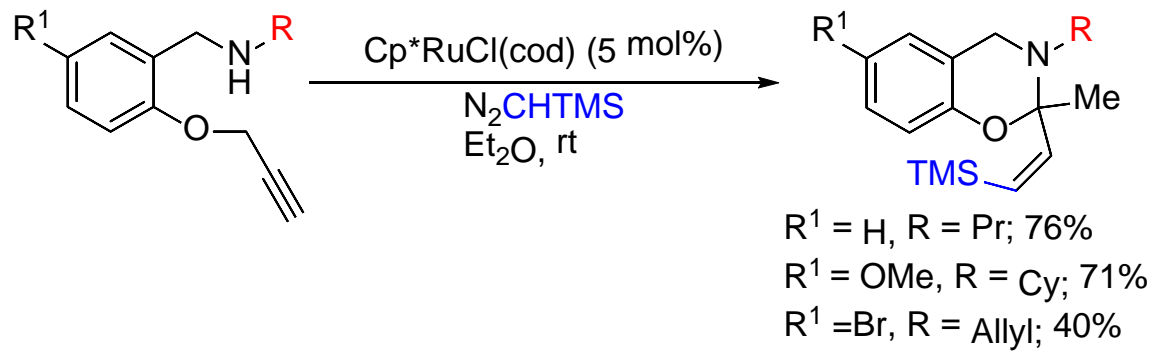

Scheme14. Ruthenium-catalyzed heterocyclization of $N$-substituted ortho-(alkynyloxy)-benzylamines to 1,3-benzoxazines.

The reaction also tolerates substrates substituted at the propargylic position. When the ortho-(alkynyloxy)benzylamine bears one methyl substituent at the propargylic position, the rearranged 2-ethyl substituted 1,3-benzoxazine was obtained in moderate yield. Similarly, when the ortho-(alkynyloxy)benzylamine bears two methyl substituents at the propargylic position, the rearranged 2-isopropyl substituted 1,3-benzoxazine was obtained in low yield (Scheme 15).

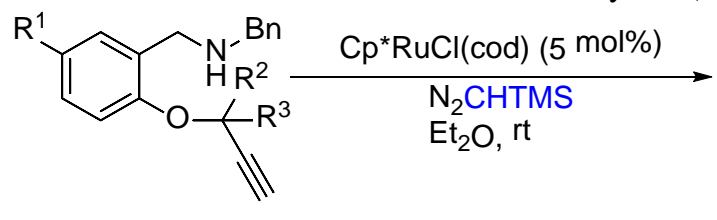

$\mathrm{R}^{1}=\mathrm{H}, \mathrm{R}^{2}=\mathrm{H}, \mathrm{R}^{3}=\mathrm{Me} ; 53 \%$

$\mathrm{R}^{1}=\mathrm{H}, \mathrm{R}^{2}=\mathrm{Me}, \mathrm{R}^{3}=\mathrm{Me} ; 28 \%$

Scheme 15. Ruthenium-catalyzed heterocyclization of propargyl substituted ortho-(alkynyloxy)benzylamines to 1,3-benzoxazines. 
The proposed mechanism would start with the smooth formation of the vinyl ruthenium intermediate $\mathbf{I I}$, in which the nitrogen lone pair might coordinate to the ruthenium to give the $18 \mathrm{e}^{-}$complex. Then, nucleophilic attack of the nitrogen to the electrophilic ruthenium carbene would afford the zwitterionic species III which could evolve by ring opening (phenoxide as good leaving group) to a transient enamine IV with recovery of catalytic species I. Finally, iminium formation from IV is trapped with the phenoxide to afford the final 1,3-benzoxazine (Scheme 16).

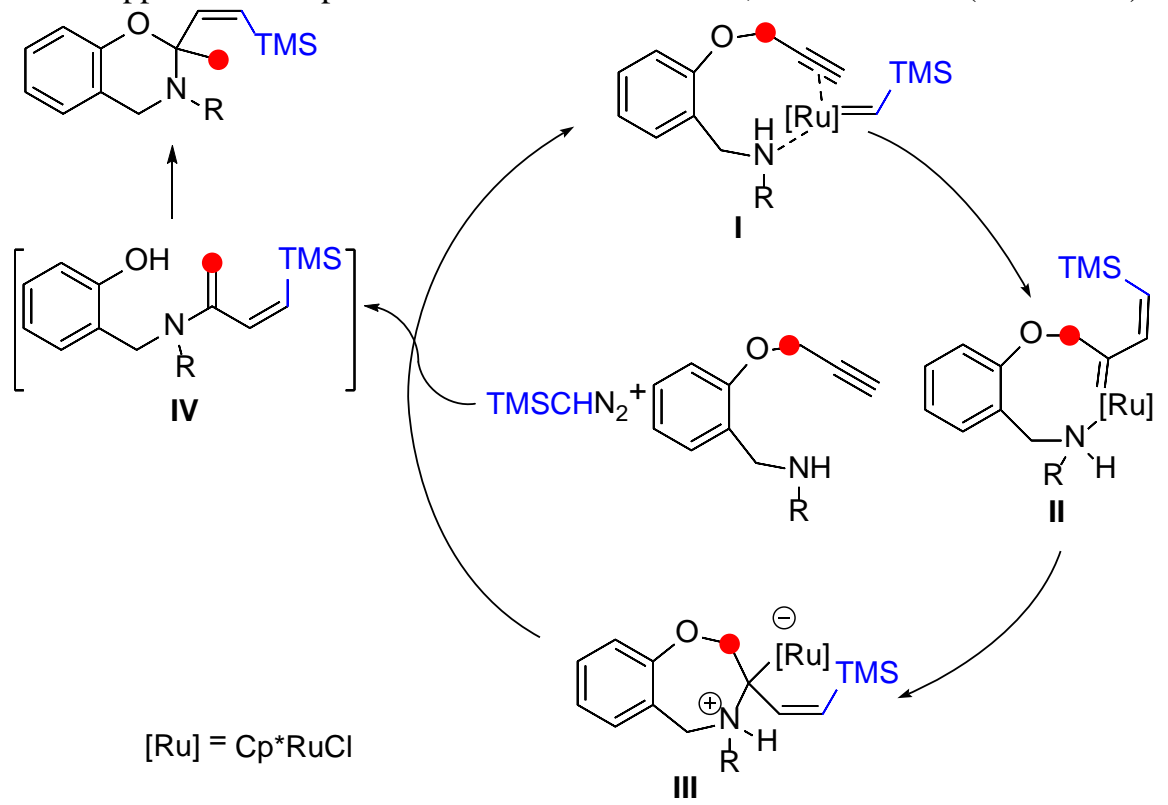

Scheme 16. Proposed mechanism for the ruthenium-catalyzed heterocyclization of otho-(alkynyloxy)benzylamines to 1,3-benzoxazines.

\section{$5 \quad$ DFT Studies of the TMS-Substituted Vinyl Ruthenium Carbenes: Formation and Stereoselective Cyclizations}

In all the previous transformations, the geometry of the double bond (stereoselectivity) of the in situ generated vinyl carbene intermediate and the final product seems to be dependent of the type of cyclization (type of mechanism), being $E$ configuration in the case of the [1,n]-hydride transfer/cyclization and $Z$ configuration for the oxygen and nitrogen nucleophilic trap of the electrophilic carbene. An early explanation for the origin of the stereoselectivity derives from the assumption of formation of the vinyl ruthenium carbene during the electrocyclic opening of ruthenacyclobutene (Scheme 1), in which the $\mathrm{Cp}^{*}$ and Y groups should be anti to avoid 
unfavorable steric interactions. If $\mathrm{Y}=\mathrm{SiMe}_{3}$, strong attractive interactions should be established between $\mathrm{SiMe}_{3}$ and $\mathrm{Cl}$ groups forcing a favourable $\mathrm{Z}$ configuration after ring-opening. On the other hand, if $\mathrm{Y} \neq \mathrm{SiMe}_{3}$ steric hindrance should be the major driving force for the torquoselectivity delivering favourable $E$-configuration of the double bond (Scheme 17).[28]

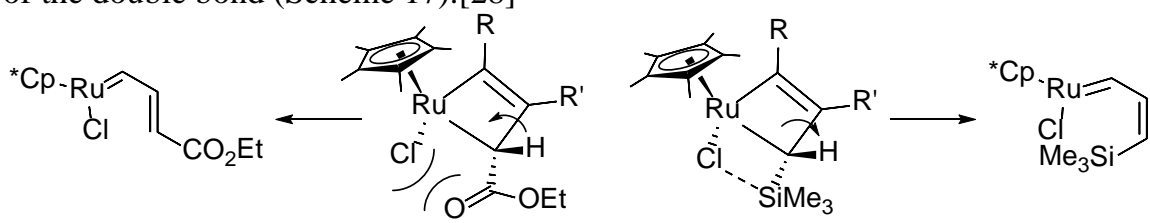

Scheme 17. Z- and E-vinyl ruthenium carbenes by ring-opening of ruthenacyclobutenes.

To clarify this early assumptions for the formation of vinyl ruthenium carbenes, we carried out DFT calculations for the [1,n]-hydride transfer/cyclization (Scheme 18).[46] The calculations showed the presence of three conformers in equilibria for the initial ruthenium carbene complex coordinated to the alkyne: a) the more stable conformer A, with the hydrogen pointing to the Cp*ring, and b) two less stable conformers $\mathbf{B}$ and $\mathbf{C}$, with the TMS group pointing to the $\mathrm{Cp}^{*}$ ring backwards and forward, respectively.

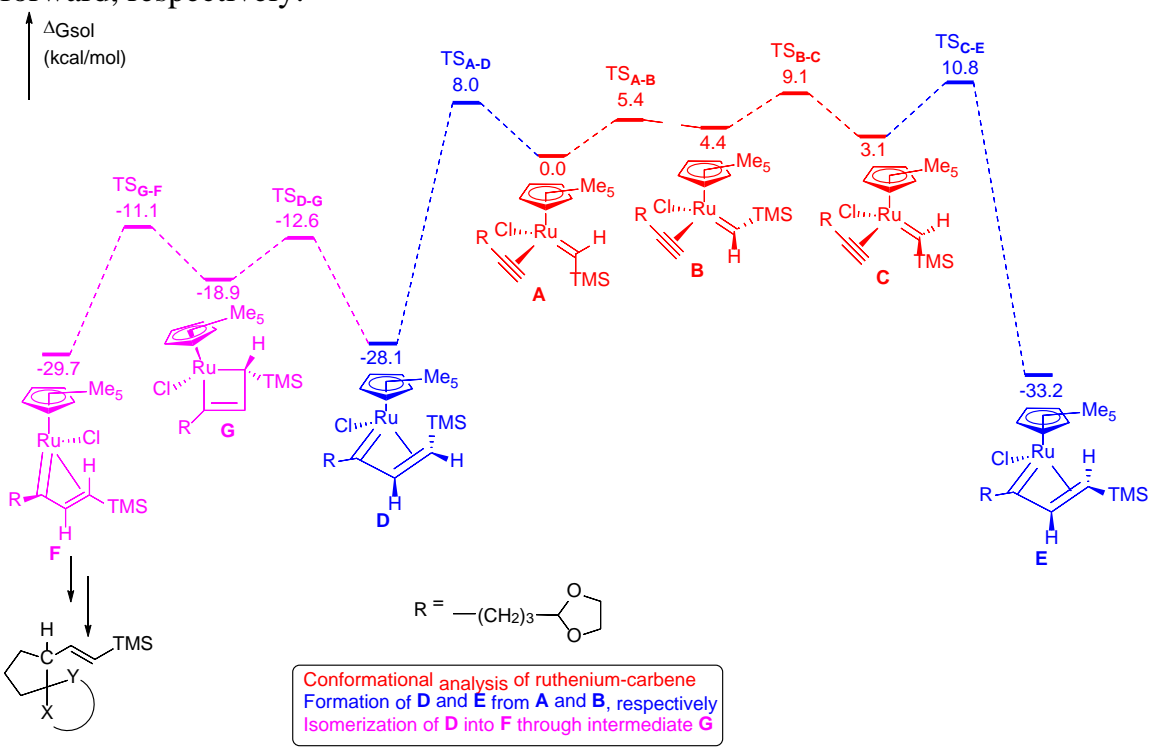

Scheme 18. Free energy profile for the conformational analysis of ruthenium carbene, formation of $\mathbf{D}, \mathbf{E}$ and isomerization of $\mathbf{D}$ to $\mathbf{F}$ for the [1,5]-hydrogen migration/cyclization of alkynylacetals using the B3LYP-D3/LANL2DZ for Ru and 6-311++G(d,p) for all other atoms, SCRF using SMD model (diethyl ether). Energies are relative to $\mathbf{A}$ and are mass balanced.

This initial ruthenium carbene complex can evolve either to the Z- or $E$ - vinyl ruthenium carbene species $\mathbf{D}$ and $\mathbf{E}$, respectively, through transition states separated 
by $2.8 \mathrm{Kcal} \mathrm{mol}^{-1}$ that favor the formation of $Z$ isomer $\mathbf{D}$. The most favorable pathway for the [1,5]-hydrogen transfer/cyclization process involved the initial isomerization of $Z$ isomer $\mathbf{D}$ to the $E$ isomer $\mathbf{F}$, distinct stereoisomer of $\mathbf{E}$, through ruthenacyclobutene intermediate $\mathbf{G}$, which could explain the $E$ geometry of the vinyl substituents of the final products in these transformations.

For the cases of vinyl ruthenium carbene intermediates that undergo nucleophilic attack either by an oxygenated (alkynals and alkynones) or nitrogenated (otho-(alkynyloxy)benzylamines) nucleophile, the most favorable pathway would start from intermediates of type $\mathbf{D}$ without isomerization, which would explain the formation of the final products bearing vinyl substituents with $Z$ geometry.

\section{Conclusions}

In summary, it has been described new modes of catalytic cyclizations from the in situ generated vinyl ruthenium carbene intermediates by the intramolecular nucleophilic attack to the carbene (Scheme 19). Complex spiro and fused bicyclic structures can be obtained by an intramolecular neutral/redox process which involves a mild formation of catalytic vinylic ruthenium carbenes from alkynyl acetals, ethers and amines which behave as hydride acceptors.

On the other hand, trapping the in situ generated catalytic vinyl ruthenium carbenes with carbonyl nucleophiles allowed the synthesis of valuable 2-vinyl dihydropyrans.

Finally, trapping the catalytic vinyl ruthenium carbenes with nitrogen nucleophiles generated from alkynyloxybenzylamines afforded the rearranged 2,2-disubstituted 1,3-benzoxazines. 

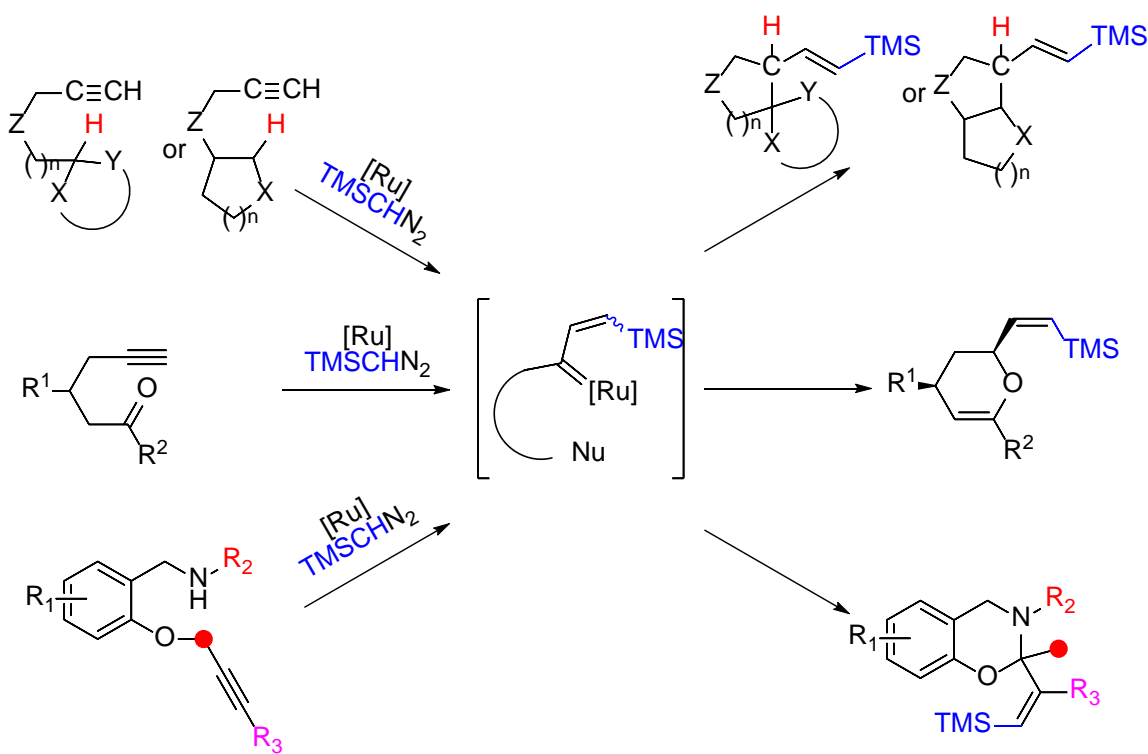

Scheme 19. New modes of catalytic cyclizations from vinyl ruthenium carbene intermediates.

Acknowledgements: This work was supported by the Spanish MINECO (project CTQ201459015R), the Xunta de Galicia (project GRC2014/032) and the European Regional Development Fund (projects CTQ2014-59015R and GRC2014/032). We also thank the ORFEO-CINQA network (CTQ2014-51912REDC). D. P. thanks XUGA for a predoctoral contract. We are also grateful to the CESGA (Xunta de Galicia) for computational time.

\section{References}

1. Moss RA, Doyle MP (eds) (2014) Contemporary Carbene Chemistry. John Wiley \& Sons, Inc., Hoboken

2. Hoveyda AH, Malcolmson SJ, Meek SJ, Zhugralin AR (2010) Angew Chem Int Ed 49:34

3. Kotha S, Dipak MK (2012) Tetrahedron 68:397

4. Fuerstner A (2013) Science 341:1357

5. Vougioukalakis GC, Grubbs RH (2010) Chem Rev 110:1746

6. Connon SJ, Blechert S (2003) Angew Chem Int Ed 42:1900

7. Nolan SP, Clavier H (2010) Chem Soc Rev 39:3305

8. Kress S, Blechert S (2012) Chem Soc Rev 41:4389

9. Grubbs RH (2004) Tetrahedron 60:7117

10. Masuda T, Higashimura T (1984) Acc Chem Res 17:51

11. Katz TJ, Sivavec TM (1985) J Am Chem Soc 107:737 
12. Fox HH, Wolf MO, O'Dell R, Lin BL, Schrock RR, Wrighton MS (1994) J Am Chem Soc $116: 2827$

13. Diver ST, Giessert AJ (2004) Chem Rev 104:1317

14. Katz TJ (2005) Angew Chem Int Ed 44:3010

15. Li J, Lee D (2011) Eur J Org Chem 2011:4269

16. Rubin M, Rubina M, Gevorgyan V (2007) Chem Rev 107:3117

17. Zaragoza Dorwald F (1998) Metal Carbenes in Organic Synthesis. Wiley-VCH, Weinheim

18. Doyle MP, McKervey MA, Ye T (1998) Modern Catalytic Methods for Organic Synthesis with Diazo Compounds: From Cyclopropanes to Ylides. Wiley, New York

19. DeAngelis A, Panish R, Fox JM (2016) Acc Chem Res 49:115

20. Ford A, Miel H, Ring A, Slattery CN, Maguire AR, McKervey MA (2015) Chem Rev 115:9981

21. Hu F, Xia Y, Ma C, Zhang Y, Wang J (2015) Chem Commun 51:7986

22. Dorel R, Echavarren AM (2015) J Org Chem 80:7321

23. Archambeau A, Miege F, Meyer C, Cossy J (2015) Acc Chem Res 48:1021

24. Qian D, Zhang J (2015) Chem Soc Rev 44:677

25. Wei F, Song C, Ma Y, Zhou L, Tung C-H, Xu Z (2015) Sci Bull 60:1479

26. Xia Y, Zhang Y, Wang J (2013) ACS Catal 3:2586

27. Vovard-Le Bray C, Derien S, Dixneuf PH (2010) C R Chim 13:292

28. Le Paih J, Vovard-Le Bray C, Derien S, Dixneuf PH (2010) J Am Chem Soc 132:7391

29. Le Paih J, Derien S, Oezdemir I, Dixneuf PH (2000) J Am Chem Soc 122:7400

30. Vovard-Le Bray C, Derien S, Dixneuf PH (2009) Angew Chem Int Ed 48:1439

31. Eckert M, Monnier F, Shchetnikov GT, Titanyuk ID, Osipov SN, Toupet L, Derien S, Dixneuf PH (2005) Org Lett 7:3741

32. Monnier F, Castillo D, Derien S, Toupet L, Dixneuf PH (2003) Angew Chem Int Ed 42:5474

33. Monnier F, Vovard-Le Bray C, Castillo D, Aubert V, Derien S, Dixneuf PH, Toupet L, Ienco A, Mealli C (2007) J Am Chem Soc 129:6037

34. Vovard-Le Bray C, Derien S, Dixneuf PH, Murakami M (2008) Synlett 193

35. Girard SA, Knauber T, Li C-J (2014) Angew Chem Int Ed 53:74

36. Rouquet G, Chatani N (2013) Angew Chem Int Ed 52:11726

37. Jazzar R, Hitce J, Renaudat A, Sofack-Kreutzer J, Baudoin O (2010) Chem Eur J 16:2654

38. Chen X, Engle KM, Wang D-H, Yu J-Q (2009) Angew Chem Int Ed 48:5094

39. Bergman RG (2007) Nature 446:391

40. Godula K, Sames D (2006) Science 312:67

41. Wang L, Xiao J (2014) Adv Synth Catal 356:1137

42. Haibach MC, Seidel D (2014) Angew Chem Int Ed 53:5010

43. Cambeiro F, López S, Varela JA, Saá C (2012) Angew Chem Int Ed 51:723

44. Cambeiro F, López S, Varela JA, Saá C (2014) Angew Chem Int Ed 53:5959

45. González-Rodríguez C, Suárez JR, Varela JA, Saá C (2015) Angew Chem Int Ed 54:2724

46. Cambeiro F, Martínez-Núñez E, Varela JA, Saá C (2015) ACS Catal 5:6255 